\title{
Community Radio: An Optimistic Voice for the Voiceless and Disillusioned Rural Community
}

\author{
Samrat Sikdar ${ }^{1 *}$, Amrita Kumar Sarkar ${ }^{1}$, Swagata Ghosal $^{2}$ and Satya Prakash ${ }^{1}$ \\ ${ }^{1}$ Department of Extension Education, Dr. Rajendra Prasad Central Agricultural University \\ (Pusa, Samastipur-848125, Bihar, India) \\ ${ }^{2}$ Department of Agricultural Extension, Bidhan Chandra Krishi Viswavidyalaya \\ (Mohanpur, Nadia-741252, West Bengal, India) \\ *Corresponding author
}

\begin{abstract}
A B S T R A C T
Community radio would act as a tempting and reliable community media weapon in socioeconomic empowerment of the underprivileged rural community. In a world with a burgeoning influence of multi-dimensional audio-visual content, community radio has managed to survive because of the 'community first' approach. It is an autonomous, nonprofit in goal; listener supported and controlled media and adopting a management structure and broadcasting style that challenges the traditions of professional media broadcasting. A truly democratic platform-community radio, in its real sense is meant to create content for the benefit of society as well as individual prosperity and empowerment. The purpose of the community radio stations is to facilitate the free flow of information by encouraging freedom of speech and by enhancing dialogue within the communities concerned in order to promote better participation by their populations. It showed the potential for agricultural extension to benefit that local broadcasting can achieve by using participatory communication approaches. Participatory communication techniques can support agricultural extension efforts especially using local languages and rural radio to communicate directly with farmers and listeners' groups for sharing of development information.
\end{abstract}

\begin{tabular}{|l|}
\hline Ke y w o r d s \\
Media, Radio, \\
Participatory, \\
Community, \\
Rural, Democratic \\
\hline Article Info \\
\hline $\begin{array}{l}\text { Accepted: } \\
18 \text { August } 2020 \\
\text { Available Online: } \\
\text { 10 September } 2020\end{array}$ \\
\hline
\end{tabular}

\section{Introduction}

Development is a process that creates growth, progress, positive change or the addition of physical, economic, environmental, social and demographic components. Typically, in the early stages of development, economies have most of their production and labour force in agriculture. Later, the manufacturing and service sectors become larger. The key feature of development is to eradicate poverty. In the second half of the 20th century, development policy makers became acutely aware of the difficulties a large number of countries in the developing world facing as most of them were former colonies of the industrialized nations. Development economics became more or less synonymous with the study of how these countries could progress out of poverty. Though, after Independence India achieved 
tremendous success in many fields but still much is needed to be done in order to become a developed nation. Statistics betrays that after Independence our growth rate has increased from $3 \%$ to $9 \%$. But, still we are facing problems like poverty, illiteracy, unemployment etc. Besides, a major chunk of population living in villages is still backward. Though the government is spending million of rupees in the name of rural development, but still it's not getting the desired results.

Now-a-days no one can deny the importance of media in fighting social evils, illiteracy as well as poverty. Understanding the essence of media and showing full confidence in it, $1^{\text {st }}$ Prime Minister of India Lt. Pt. Nehru took all possible measures to make Press free from any authoritarian control. Media has played pivotal role in spreading knowledge in traditional societies where accessing education was just a dream. By regularly broadcasting programs on agricultural issues and on various social and moral evils, media has contributed a lot in bringing multifarious development in this nation. Still the nation is facing problems like poverty, illiteracy, unemployment etc. That's because our population has multiplied at an alarming level though the available resources more or less remain the same.

Besides economic development it's very necessary to facilitate social, ethical as well community based development in order to avoid chaos in the near future.

As, $67 \%$ of our population still dwell in villages, so how could we think of becoming a super power without empowering the rural area of our nation. Thus understanding the importance of rural uplifting, our Government has increased the annual rural development budget. Besides, the central as well as state government has devised various developmental schemes in order to improve the conditions of rural areas.
The provision of information and skills has gained popularity in the quest to empower communities with Community Radio as a unique and effective tool. Chapman et al., (2003) reported that the growth of rural radio stations reflects both the improvements in information technologies and the shifting of development paradigm towards a more participatory style of information and knowledge transfer. Community Radio was identified as an avenue for participatory communication and as a tool relevant in both economic and social development.

\section{Challenges of $21^{\text {st }}$ century in rural empowerment}

Though the government is spending million of rupees in the name of rural development, but still it's not getting the desired results. There can be many reasons behind this. But the first and the foremost reason is the communication gap between government devised policies and common masses. Though, the policies are extremely good, but common masses remain ignorant regarding them because of lack of information, illiteracy, proper guidance and lack of training in this field. Thus, hardly these policies remain relevant in the layman's context and due to this a very small section of citizens is benefited by them. In order to bridge this gap, a firm communication policy will prove crucial. According to this policy, local community media should be promoted in order to enhance community development, at least at grass root level. Mass media like radio, television, newspaper and farm magazine provide relevant and timely information to farmers (Sikdar et al., 2020). Among various existing genres of local community media, Community Radio will prove most effective as it can easily cover a wider range of area as well as audience. Besides, Government should also take firm 
step to check prevailing corruption in Government offices as well as various public sectors for enhancing empowerment of the rural underprivileged masses.

\section{Community radio-a holistic illustration}

Community radio is a type of radio service that caters to the interests of a certain area, broadcasting content that is popular to a local audience but which may often be overlooked by commercial or mass-media broadcasters. The term has somewhat different meanings in the United Kingdom, the United States, Canada, and Australia. In the UK, the idea of community-based services can be traced back at least as far as the original concept for BBC local radio in the early 1960s. Thereafter various land-based unlicensed pirate radio stations (Such as East London Radio, and Radio AMY (Alternative Media for You)) developed the idea further. Although, "community radio" remains synonymous with "pirate radio" for some people in the UK, most minority immigrant stations focused purely on specific musical genres and were operated (theoretically at least) on a for-profit basis. Community radio services in the UK are operated on a not-for-profit basis with community ownership and control built in to their structures. In the U.S., community radio stations are non-profit, community-based operations licensed by the Federal Communications Commission for broadcasting in the non commercial, public portion of the FM band. These stations differ from other public radio outlets in the U.S. by allowing community volunteers to actively participate as broadcasters.

Community radio is a type of radio service that offers a model of radio broadcasting beyond commercial and public service. Community radio broadcasting serves geographic communities and communities' interest. The content of broadcasting is largely popular and relevant to a local/specific audience but which may often be overlooked by commercial or mass-media broadcasters. Community radio stations are operated, owned, and driven by the communities they serve. Community radio is not-for-profit and provides a mechanism for facilitating individuals, groups, and communities to tell their own diverse stories, to share experiences, and in a media rich world to become active creators and contributors of media. In many parts of the world today, community radio acts as a vehicle for the community and voluntary sector, civil society, agencies, NGOs and citizens to work in partnership to promote community development. By the core aims and objectives of this model of broadcasting, community radio stations often serve their listeners by offering a variety of content that is not necessarily provided by the larger commercial radio stations.

Community radio can play a significant role at the grassroots level for rural development. For instance, issues of poverty, agriculture, gender inequality, education, social problems among others could be the focus for programming. Chapman et al., (2003) found that rural radio is effective in improving the sharing of agricultural information by remote rural farming communities. Radio in this regard provides a set of participatory communication techniques that support agricultural extension efforts by using local languages to communicate directly with farmers and listeners' groups. Using the Most Significant Change (MSC) process, Walters et al., (2011) assessed the impact of community radio in Indonesia and concluded that effective radio activities can make a significant change in a community's life. The MSC methodology has its origins in community health development debates. It has recently been applied to community radio impact evaluation. By the MSC process, 
community members provide feedback in the form of stories describing the desirable change in their life as a result of the activities of the radio. Through media skills training and access to the airwaves, a community radio facilitates a number of capacity building activities.

The exchange of information, networking of groups, the provision of skills and training and these undoubtedly are key elements of developing a community. Again, a radio facility for a community facilitates the promotion of awareness of community groups and facilities in the area as well as providing the avenue for the empowerment of these groups to use radio to promote themselves and to speak directly to the community. For its proximate location to its clients a Community Radio serves a local community of its interest. It is accessible to the community in terms of ownership, decision making and programme output. In majority of cases, programming is produced by the community, with focus on local concerns and issues. Unlike in the case of the mainstream media, rather than merely talking about the community, the people themselves make the programmes. This strengthens local culture with the recognition that this is their station; it becomes a forum for a wide diversity of local opinions and views. Sterling et al., (2007) provided evidence that female community radio listeners are given a voice with which to respond to programming and to create programming content. By employing the principles of Participatory Action Research (PAR), it was found that women will be more likely to benefit from technology-mediated opportunities for development if they themselves produce information that contributes to their advancement, rather than simply consuming information provided by others (Sterling et al., 2007).

Economic theory postulates that Community Radio, to a large extent, if effectively organized, performs three main significant functions at the grass root level for rural development. Firstly, it promotes issues of agriculture, gender equality, education trade and commerce, disaster, weather, natural calamities, poverty and social problems. Community radio is usually for the people, run by the people and owned by the people. Secondly, it enhances the capacities of local people to work together to tackle a range of social problems, including poverty and exclusion through radio. Lastly, it contributes to nurturing of the creative talents of the community and providing a forum for a diversity of opinions and information. For that, a vibrant effort on behalf of public as well as private extension bodies must be put into action along with the clients themselves. There should be concerted drive to induce sense of unique venture in farmers through motivational drives (Prakash et al., 2019).

\section{Community radio and its various models}

Philosophically two distinct approaches to community radio can be discerned, though the models are not necessarily mutually exclusive. One stresses service or community mindedness, a focus on what the station can do for the community. The other stresses involvement and participation by the listener.

Within the service model localism is often prized, as community radio, as a third tier, can provide content focused on a more local or particular community than larger operations. Sometimes, though, the provision of syndicated content that is not already available within the station's service area is seen as a desirable form of service. Within the access or participatory model, the participation of community members in producing content is seen as a good in itself. While this model does not necessarily exclude a service approach, there is a tension between the two. 


\section{Vision and philosophy}

Modern-day community radio stations often serve their listeners by offering a variety of content that is not necessarily provided by the larger commercial radio stations. Community radio outlets may carry news and information programming geared toward the local area, particularly immigrant or minority groups that are poorly served by other major media outlets. More specialized musical shows like folk music are also often a feature of many community radio stations. Community stations and pirate stations (where they are tolerated) can be valuable assets for a region. Community radio stations typically avoid content found on commercial outlets, such as Top 40 music, sports etc.

\section{Community radio landscape in India}

In India, the campaign to legitimise community radio began in the mid 1990s, soon after the Supreme Court of India ruled in its judgment of February 1995 that "airwaves are public property". This came as an inspiration to groups across the country, but to begin with, only educational (campus) radio stations were allowed, under somewhat stringent conditions.

Anna FM is India's first campus 'community' radio, launched on 1 February 2004, which is run by Education and Multimedia Research Centre $\left(\mathrm{EM}^{2} \mathrm{RC}\right)$, and all programmes are produced by the students of Media Sciences at Anna University. On 16 November 2006, the government of India notified new Community Radio Guidelines which permit NGOs and other civil society organizations to own and operate community radio stations. About 4,000 community radio licenses are on offer across India, according to government sources. By 30 November 2008, the ministry of Information and broadcasting, Government of India, had received 297 applications for community radio licenses, including 141 from NGOs and other civil society organizations, 105 from educational institutions and 51 for 'farm radio' stations to be run by agricultural universities and agricultural extension centres (Krishi Vigyan Kendras). Of these, 107 community radio stations have been cleared for licensing through the issue of Letters of Intent. 13 Grant of Permission Agreements (GOPA) has been signed with license applicants under the new scheme. By 30 November 2008, there were 38 operational community radio stations in the country. Of these, two are run by NGOs and the rest by educational institutions. The first communitybased radio station, licensed to an NGO (as distinct from campus-based radio) was launched on 15 October 2008, when 'Sangham Radio' in Pastapur village, Medak district, Andhra Pradesh state, was switched on at 11.00am. Sangham Radio, which broadcasts on $90.4 \mathrm{MHz}$, is licensed to Deccan Development Society (DDS), an NGO that works with women's groups in about 75 villages of Andhra Pradesh. The community radio station is managed by 'General' Narsamma and Algole Narsamma. The second NGO-led community radio station in India was launched on 23 October 2008 at 'TARAgram' in Orchha, Madhya Pradesh state named 'Radio Bundelkhand' after the Bundelkhand region of central India where it is located, the radio station is licensed to the Society for Development Alternatives (DA), a Delhi-based NGO. Radio Bundelkhand also broadcasts on $90.4 \mathrm{MHz}$ for four hours a day, including two hours of repeat broadcast.

By 9 July 2009, the Ministry of Information and Broadcasting had issued 'Grant of Permission Agreements' (GOPA) for 51 community radio stations. Most of the GOPAs were issued to educational institutions. Among the community radio stations started in 2009, SARANG 107.8 is the only one in Karnataka, though there are 
few more which has received SACFA (Standing Committee Clearance for Frequency Allocation). Under the new community radio policy, any not-for-profit 'legal entity' - except individuals, political parties and their affiliates, criminal and banned organizations - can apply for a CR license. Central funding is not available for such stations, and there are stringent restrictions on fundraising from other sources. Only organisations that are registered for a minimum of three years old and with a 'proven' track record of local community service can apply. License conditions implicitly favour well-funded stations as against inexpensive low power operations, several of which (e.g. Mana Radio in Andhra
Pradesh and Raghav FM in Bihar) ran successfully on shoe-string budgets before the imposition of any community radio policy. Presently, about 179 ongoing CR stations are playing in a full-flezed manner and the figure is quite annoying on an overall basis. If states of eastern India are focussed, a variety of views are obtained regarding the status (number) of operational CR stations, GOPA signed and LOI holders. These are presented below with pie chart along with an interstate comparative analysis with the bar diagram. Moreover, Manipur and Tripura are strikingly suffering from the lacuna of having operational CR stations (Fig. 1 and 2; Table $1)$.

Table.1 Present status of CR in the major provinces of Eastern India

\begin{tabular}{|c|c|c|c|}
\hline State & Operational CR station & GOPA signed & LOI Holder \\
\hline Bihar & 04 & 02 & 32 \\
\hline Assam & 02 & 00 & 15 \\
\hline West Bengal & 03 & 01 & 00 \\
\hline Jharkhand & 01 & 00 & 04 \\
\hline Manipur & 00 & 00 & 03 \\
\hline Tripura & 00 & 01 & 00 \\
\hline
\end{tabular}

(Source: CR website, Ministry of Information and Broadcasting, Govt. of India)

Fig.1 The state-wise analysis of no. of operational CR stations, LOI holder and GOPA signed (major East Indian provinces)

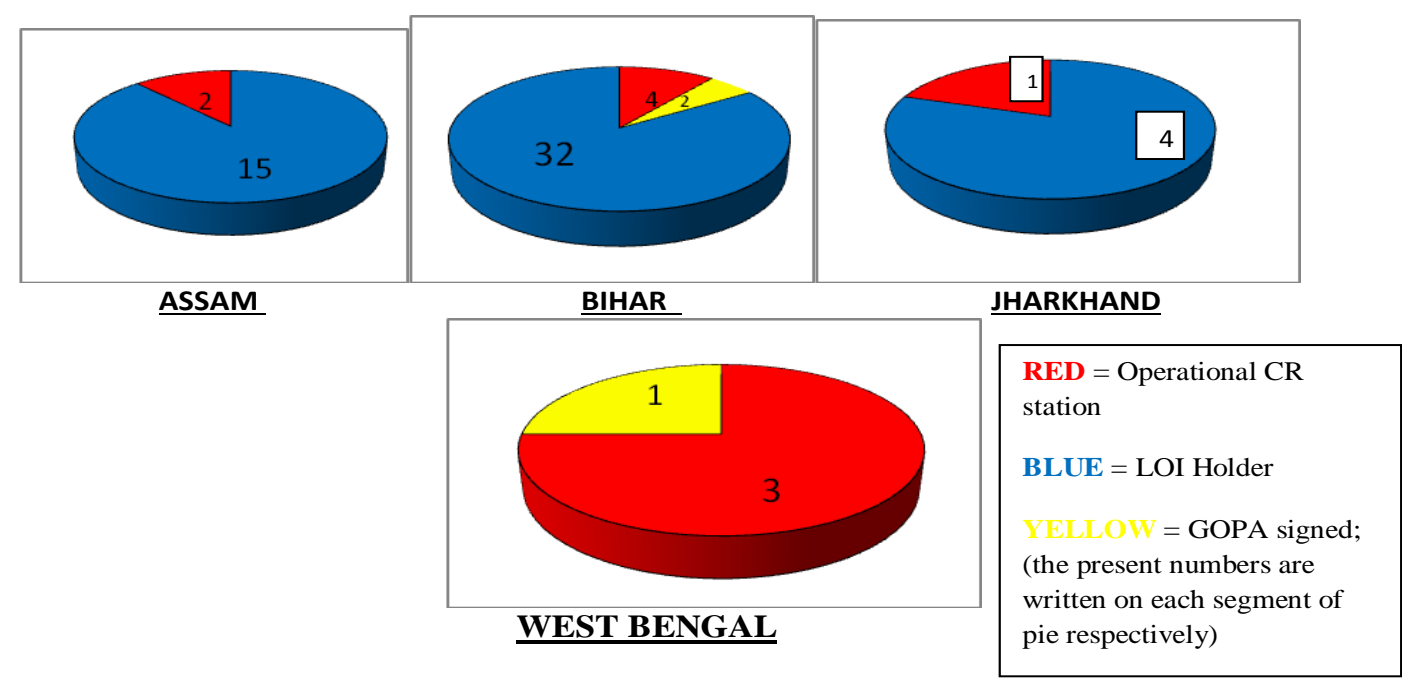


Fig.2 The interstate comparative analysis of no. of operational CR stations (major East Indian provinces

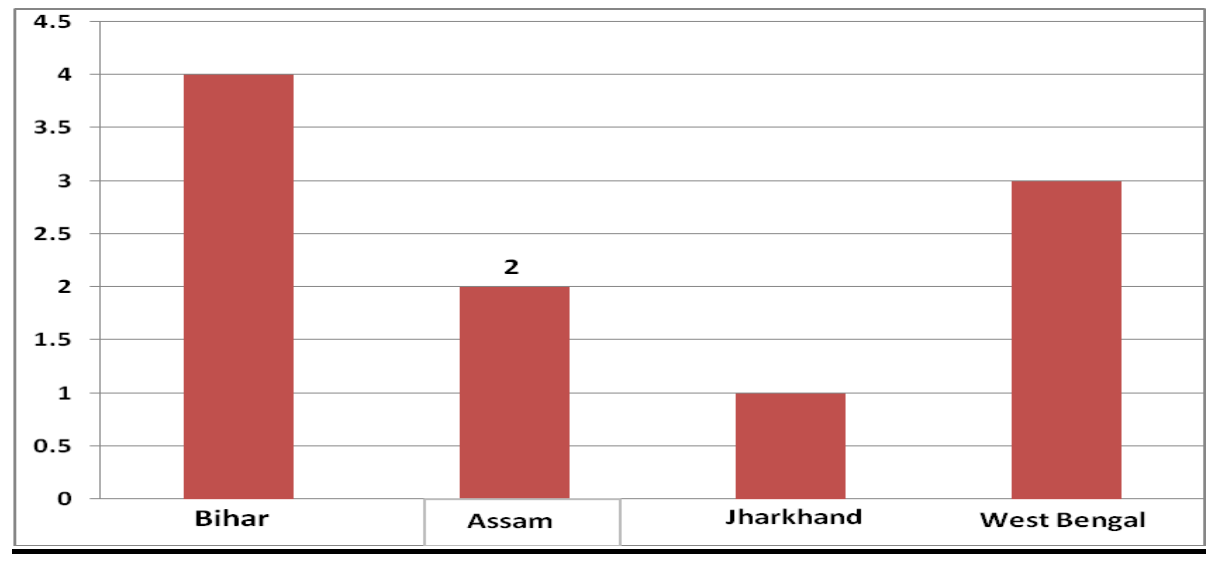

The licence entitles them to operate a 100 watt (ERP) radio station, with a coverage area of approximately 12 kilometres radius. A maximum antenna height of 30 meters is allowed. Community radio stations are expected to produce at least $50 \%$ of their programmes locally, as far as possible in the local language or dialect. The stress is on developmental programming, though there is no explicit ban on entertainment. News programmes are banned on community radio in India, as also on commercial FM radio. However, the government recently clarified that certain categories of news are permitted on radio, including sports news and commentaries, information on traffic and weather conditions, coverage of cultural events and festivals, information on academic events, public announcements pertaining to utilities like electricity and water supply, disaster warnings and health alerts. Five minutes of advertising per hour is allowed on community radio. Sponsored programs are not allowed except when the program is sponsored by the Government at the Centre or State.

Activists and community workers from across the country have banded together under the aegis of the 'Community Radio Forum' in order to coordinate training and support for community radio stations, as well as to continue to petition for a more proactive community radio policy. The Community Radio Forum, India, was registered as a 'Society' and 'Trust' on 26 February 2008. In the meantime, mobile telephone operators have begun to offer commercial broadcast services over GSM, evading completely government restrictions built around traditional concepts of broadcasting technology.

\section{Some successful and prominent examples of community radios in India}

SARANG 107.8 FM: SARANG 107.8 is run by St Aloysius College (Autonomous), Mangalore, a coastal town in the southern part of Karnataka. SARANG 107.8 FM means 'all colours' of Mangalore signifying various social, religious, linguistic communities and their harmonious. The local communities of farmers, fisher folk, medical/ legal experts, students, workers contribute regularly to this radio. The radio also spreads messages of peace and harmony among people through programmes based on the need for the same. Health and hygiene, agricultural messages, fisher folk issues, road safety, water conservation, rain water harvesting, folk culture and life, original entertainment by 
locals and students are the hall mark of this radio. Currently SARANG 107.8 broadcasts in Konkani, Kannada, Tulu, and English languages regularly, besides occasionally broadcasting in Malayalam and Beary languages.

KUNJAL PANCHHI KUTCH JI: This community radio station is administered by Kach Women Development Corporation and is immensely popular among the rural womenfolk. This corporation is working in this area since last two decades. This radio station mostly focuses on the issues relating to women and tries to find a solution to all the problems being discussed here. The topic for discussion mostly consists of issues like female foeticide, dowry and female education.

CHALA HO GAON MEIN: The importance of this community radio lies in the fact that the programs broadcasted here is prepared by the people belonging to rural background. The programs basically cover issues like dowry, violence against women, corruption, social evils etc. Needless to say that 'Chalo Ho Gao $M e$ ' has really proved to be a landmark in providing common platform to the residents of Palamu district of Jharkhand from where they can communicate their thoughts without any restriction.

MANDAKINI KI AWAAZ: 'Mandakini $k i$ Awaaz' Community Radio is located in Mandakini river valley at Pauri in Garhwal, supported by a group of people from a tiny village called Bhanaj. Located at a 5 hour drive from the nearest town centre of Rudraprayag, this group of people aims at creating an open and transparent administrative and governance information system. The radio group mediates between the people and the governing bodies (panchayats) of these villages, in order to create an open platform where policies, schemes and financial budgets can be made available for public discussion and scrutiny. It was established with required technical support and training from Ideosync Media Combine and Equal Access, the two NGOs working in the field of development communication and long standing partners of community radio.

JYOTIRGAMAYA: $\quad 91.2 \mathrm{MHz}$, Jyotirgamaya, the CRS (Community Radio Station) of the Panjab University is being run by the School of Communication Studies. It was inaugurated on 13th February, 2011 and is acting as a unifying agent amongst the university faculty, students and also the community. The station proudly offers four broadcasts a day that includes a total of nine programs running for over 10 hours. The CRS is recipient of a DST grant to run its special programme on Science for Women Health and Nutrition. The Public Relations Council of India awarded the special programme 'Hamari Beti' run by PU CRS. The PU Radio has collaborated with BBC Media Action Group and UNICEF to produce a programme for adolescents called, 'Full on Nikki'. The programmes of Radio Jyotirgamaya can be heard for $10 \mathrm{kms}$ radius.

PANTNAGAR JANVANI: Pantnagar Janvani was launched on 15 August 2011 by G B Pant University of Agriculture and Technology (Pantnagar, Uttarakhand). This community radio deals with the agricultural development, farmers' development, women empowerment, rural development and also with the various issues of 80 villages nearby. The major challenge in front of the station is its diverse communities. People in its neighbourhood speak Punjabi, Bengali, Gadwali, Kumaoni, Bhojpuri and Urdu. The station produces programmes in Hindi, which can be understood by most of these communities, though it records folk songs of different languages. One of the successes of this radio station is that local stations of All India Radio depend up on the station for its agriculture programme. 


\section{Problems of community radio}

The first major problem for the Community Radios is the funding and payments of the spectrum fees. Every community Radio needs funds to run it smoothly. Nevertheless, those who have taken up the cause go from village to village and mountain to mountain with a small recorder player, helping people to communicate. In April 2012, the Government had hiked the spectrum fee from 19700 to Rs. 91000. This fivefold increase in the license fee provoked widespread protest from functional community radio stations. The second problem is that many girls are active in the community Radios and when these girls get married, the group comes to a standstill.

In conclusion the real sense, community radio plays a pivotal role in making the masses aware about their basic rights and duties. Not only limited to solving problems which a common man faces in his day-to-day life, community radio provides him a strong platform from where he can freely disseminate his ideas among his community members in the best possible manner. Thus, community radio becomes one of the important instruments in strengthening our 'Right to Freedom of Speech and Expression'. Besides solving social problems as well as entertaining local people, community radio also acts as an intermediary between the Government and the local masses. This is the place from where local people can air their grievances to the Government as well as get the solutions to their problems too. Needless to say, community radio has played a major role in bridging the communication gap between the Government and the local people. As, the community radio is still evolving it might be possible that in the near future, we will witness its various new forms which will be technologically more superior as well as user-friendly. Whatever the case may be, community radio has proved to be one of the best medium of communication at the grassroot level.

\section{References}

Barr A. (2005), "The contribution of Research to Community Development". Community Development Journal; 40(4): 453-458.

Chapman R., Blench R., KranjacBerisavljevic' G. and Zakariah A.B.T. (2003). "Rural Radio in Agricultural Extension: the Example of Vernacular Radio Programmes on Soil and Water Conservation in Northern Ghana"; Agricultural Research and Extension Network; Network Paper No. 127 January 2003 ISBN 0850036402. http://en.wikipedia.org/wiki/Economy_ of_Indiahttps://mib.gov.in/ http://uccommedia.in/news/pantnagarjanvani-not-just-a-farmers-radio/. Nov 15,2013

Dagron A. (2001), "Making waves: stories of participatory communication for social change". New York: The Rockefeller Foundation.

Dunaway, Ph.D., David (2002). Jankowski, Nicholas W.; Prehn, Ole. eds."Community Radio at the Beginning of the 21st Century: Commercialism vs. Community Power" (pdf). Community Media in the Information Age: Perspectives and Prospects (Cresskill, NJ: Hampton Press).http://www.javnostthepublic.org/media/datoteke/1998-2dunaway.pdf. Retrieved 2009-02-15 http://en.wikipedia.org/wiki/Community radio http://www.i4donline.net/July07/1337.p df

Kumari, S. and Prakash, S. (2019). Study on Level of Knowledge and Attitude of Farmers towards System of Wheat Intensification (SWI) Technology in 
Samastipur District of Bihar, India. International Journal of Current Microbiology and Applied Sciences, 8(12), 1047-1054. https://doi.org/10.20546/ijcmas.2019.81 2.133

Rolls S. And Narayan D. (2008), "Empowering communities, informing policy: the potential of community radio". Suva: Quality Print.

Sikdar, S., Prakash, S., and Kumari, S. (2020). Analysing the Demographic and Socio-personal Characteristics of 'System of Wheat Intensification' (SWI) Adopter as well as Non-adopter Farmers: A Study in Samastipur District of Bihar State, India. International Journal of Current Microbiology and
Applied Sciences, 9(4), 476-485. https://doi.org/10.20546/ijcmas.2020.90 4.056

Sterling S., O’Brien J., and Bennett J. (2007), "Advancement through Interactive Radio" Information Systems Frontiers Volume 11 Issue 2, April 2009.

Van Vlaenderen H. (2004), Community Development Research: Merging Communities of Practice. Community Development Journal; 39(2): 135-143.

Waters D, James R. and Darby J. (2011) "Health Promoting Community Radio in Rural Bali: an Impact Evaluation". Rural and Remote Health 11 (online), 2011: 1555. Available from: http://www.rrh.org.au

\section{How to cite this article:}

Samrat Sikdar, Amrita Kumar Sarkar, Swagata Ghosal and Satya Prakash. 2020. Community Radio: An Optimistic Voice for the Voiceless and Disillusioned Rural Community. Int.J.Curr.Microbiol.App.Sci. 9(09): 2807-2816. doi: https://doi.org/10.20546/ijcmas.2020.909.347 